\title{
ANALISIS KEBERLANJUTAN USAHATANI BELIMBING DI DESA WARINGINSARI KECAMATAN LANGENSARI KOTA BANJAR
}

\author{
ANALYSIS OF SUSTAINABILITY OF BELIMING BUSINESS \\ IN WARINGINSARI VILLAGE, KECAMATAN LANGENSARI BANJAR CITY
}

\author{
HASBI ASSIDIKI ${ }^{1}$ *, DINI ROCHDIANI ${ }^{2}$, MUHAMAD NURDIN YUSUF ${ }^{1}$ \\ ${ }^{1}$ Fakultas Pertanian Universitas Galuh \\ ${ }^{2}$ Fakultas Pertanian Universitas Padjajaran \\ *Email: assidikihasbi9@gmail.com
}

\begin{abstract}
ABSTRAK
Belimbing merupakan salah satu komoditas hortikultura unggulan di Desa Waringinsari. Usahatani belimbing merupakan salah satu kegiatan kehidupan masyarakat di Desa Waringinsari. Kegiatan usahatani belimbing di Desa Waringinsari mampu memberikan kontribusi yang cukup besar bagi masyarakat di desa tersebut. Selain itu kondisi geografis di Desa Waringinsari sangat mendukung dan sangat sesuai bagi usaha budidaya tanaman belimbing sehingga hal ini menunjang bagi berjalannya usahatani belimbing di desa tersebut. penelitian : (1) Mengetahui kelayakan finansial usahatani belimbing di Desa Waringinsari (2) titik impas usahatani belimbing dilihat dari volume produksi dan penjualannya di Desa Waringinsari (3) keberlanjutan usahatani belimbing di Desa Waringinsari. Penelitian dilakukan di Desa Waringinsari menggunakan metode survey dengan sampel penelitian terdiri dari 25 petani.. Data dianalisis menggunakan analisis deskriptif kuantitatif dan deskriptif kualitatif. Alat analisis yang digunakan adalah (1) analisis kelayakan finansial (2) analisis titik impas (3) analisis keberlanjutan (belimbing ). Hasil penelitian menunjukkan bahwa : (1) Secara finansial usahatani belimbing di Desa Waringinsari layak untuk diusahakan karena telah memenuhi kriteria kelayakan finansial yang terdiri dari Net Present Value (NPV), Net Benefit Cost Ratio (Net B/C), Internal Rate of Return (IRR),dan Payback Period (PP) (2) Titik impas Break Even Point (BEP) volume produksi adalah 101,56 kilogram dengan penjualan Rp12.000;- perkilo, yang artinya usahatani belimbing tidak mengalami untung dan tidak merugi . (3) Keberlanjutan usahatani belimbing di Desa Waringinsari dapat berlanjut dimana dimensi ekonomi berada status sangat berkelanjutan dan dimensi sosial, dan ekologi berada pada status cukup berkelanjutan.
\end{abstract}

Kata kunci : Belimbing, usahatani, kelayakan finansial, BEP, keberlanjutan

\begin{abstract}
Starfruit is one of the leading horticultural commodities in Waringinsari Village. Starfruit farming is one of the activities of community life in Waringinsari Village. The star fruit farming activities in Waringinsari Village are able to provide a large enough contribution to the community in the village. In addition, the geographic conditions in Waringinsari Village are very supportive and very suitable for the cultivation of star fruit so that this supports the running of starfruit farming in the village. The objectives of the study were: (1) how is the financial feasibility of starfruit farming in Waringinsari Village (2) What is the break-even point for star fruit farming seen from the volume of production and sales in Waringinsari Village (3) to assess the sustainability of star fruit farming in Waringinsari Village The research was conducted in Waringinsari Village using a survey method. The research sample consisted of 25 farmers. The data were analyzed using quantitative descriptive analysis and qualitative descriptive analysis. The analytical tools used are (1) financial feasibility analysis (2) breakeven analysis (3) sustainability analysis (starfruit). The results showed that: (1) Financially, starfruit farming in Waringinsari Village is feasible because it has met the financial feasibility criteria consisting of Net Present Value (NPV), Net Benefit Cost Ratio (Net B / C), Internal Rate of Return ( $I R R$ ), and Payback Period (PP) (2) The break even point (BEP) of production volume is 101.56 kilograms with sales of IDR 12,000 per kilo, which means that starfruit farming is neither profitable
\end{abstract}


nor loss. (3) The sustainability of starfruit farming in Waringinsari Village can be continued where the economic dimension is in a very sustainable status and the social dimension, and the ecology is in a fairly sustainable status.

Key words: Star fruit, farming, financial feasibility, BEP, sustainability

\section{PENDAHULUAN}

Indonesia memiliki iklim tropis dan memiliki keunggulan lahan yang subur serta kaya akan berbagai jenis sumberdaya alamnya. Kelimpahan ini memberikan potensi yang sangat besar bagi Indonesia untuk mengembangkan sektor pertanian.Sektor pertanian merupakan salah satu sektor andalan dalam pembangunan perekonomian nasional. Peranan sektor pertanian sangat besar yaitu sebagaipenyumbang Produk Domestik Bruto (PDB), penyediaan sumber devisa melaluiekspor, penyediaan pangan dan bahan baku industri, pengentasan kemiskinan,penyediaan lapangan kerja, dan perbaikan pendapatan masyarakat (DirektoratJenderal, Hortikultura 2013).

Badan Pusat Statistik Nasional (2018), menyatakan bahwa di Indonesia tanaman buah belimbing berkembang hampir di seluruh nusantara yang menunjang pada peningkatan pendapatan. Hal ini setidaknya membuktikan bahwa belimbing banyak diminati petani di Indonesia. Produksi belimbing di Indonesia mencapai 101.553 ton yang tersebar di 34 Provinsi dan salah satunya adalah Provinsi
Jawa Barat, yaitu produksinya mencapai 10.421 ton yang dihasilkan dari 78.963 pohon.

Kota Banjar merupakan salah satu sentra produksi belimbing daerah di Jawa Barat yang memiliki potensi ekonomi cukup tinggi. Belimbing merupakan komoditas unggulan yang dikembangkan oleh Kota Banjar yang berpusat di Kecamatan Langensari, hal ini dapat dilihat dari jumlah produksi yang tinggi dibandingkan dengan Kecamatan lain. Menurut Dinas Ketahanan Pangan, Pertanian dan Perikanan Kota Banjar (2019), bahwa pada tahun 2018 produksi buah belimbing di Kota Banjar mencapai 338 kwintal yang secara dominan disumbang oleh Kecamatan Langensari.

$$
\text { Balai Penyuluhan Pertanian }
$$
Kecamatan Langensari (2019) menyatakan bahwa Desa Waringinsari merupakan penghasil belimbing yang terbesar di Kecamatan Langensari dengan jumlah pohon 3 ribu pohon dan luas 10 hektar. Setiap satu pohon bisa menghasilkan paling tinggi buahnya yaitu $33 \mathrm{~kg}$ per pohon, Melihat potensi produksi yang sangat besar, maka Desa Waringinsari 
dijadikan sebagai desa pengembangan buah belimbing di Kota Banjar.

Keberlanjutan usahatani belimbing di Kota Banjar sangat dipengaruhi oleh karakteristik petani dan pendapatan yang diperolehnya. Hal ini mengingat petani belimbing di Desa Waringinsari Kecamatan Langensari dalam menjalankan usahatani belimbing masih menggunakan cara-cara tradisional dan hanya berdasarkan pada pengalaman, belum ada yang melakukan perhitungan-perhitungan mengenai input dan output produksi. Para petani belimbing hampir tidak pernah meghitung untung rugi usahataninya dan para petani juga tidak pernah menghitung mengenai batas minimal volume produksi dan penjualan usahatani belimbing supaya tidak untung dan tidak rugi (impas). Untuk mendapatkan kepastian keuntungan, kelayakan dalam usahatani belimbing, dan keberlanjutannya, perlu dipertimbangkan pula faktor-faktor yang termasuk dalam input produksi, produksi, serta harga jual. Saida dkk (2011) menyatakan kestabilan harga buah harus memiliki kestabilan harga jangka panjang supaya para pelaku usahatani belimbing tidak merugi, selain itu kepemilihan lahan juga harus di perhatikan masih banyak petani yang melakukan penggarapan dilahan bukan miliknya yang mengakibatkan banyaknya pengeluaran.

\section{METODE PENELITIAN}

Jenis penelitian yang digunakan adalah metode survai. Menurut Sugiyono (2017), survei adalah metode yang digunakan untuk mendapatkan data dari tempat tertentu melalui pengumpulan data, misalnya dengan mengedarkan kuesioner, tes, wawancara terstruktur, dan sebagainya.

Sampel pada petani ini diambil secara sensus, yaitu seluruh petani belimbing sebanyak 25 orang, Penggunaan metode sensus ini berlaku jika anggota populasi relatif kecil (Usman, 2009, Ari kunto,2013).

Teknik pengumpulan data yang digunakan dalam penelitian ini meliputi data primer dan data sekunder. Data primer diperoleh dari petani usahatani belimbing melalui wawancara langsung dengan menggunakan kuesioner sebagai alat bantu yang telah dipersiapkan sebelumnya.Sedangkan data skunder diperoleh dari dinas atau intansi yang terkait dengan penelitian ini dan dari studi kepustakaan.

Untuk menganalisis kelayakan usahatani belimbing digunakan analisis kelayakan, untuk menganalisis titik impas digunakan analisis break even point, dan 
untuk menganalisis keberlanjutan usahatani dianalisis secara deskriptif. Untuk menghiting kelayakan usahatani belimbing di Desa Waringinsari menggunakan rumus sebagai berikut

\section{a. Net Present Value (NPV)}

Menurut Gittinger (2008), suatu proyek dinyatakan layak apabila mamfaat yang didapat melebihi (paling tidak sama dengan) biaya yang dikeluarkan. NPV merupakan selisih antara nilai manfaat dan biaya pada tahun tersebut. NPV artinya kegiatan usahatani layak untuk dilaksanakan karena manfaat yang didapalebih besar dibanding biaya yang dikeluarkan, dengan rumus:

$N P V=\sum_{t=0}^{t=n} \frac{B_{t}-C_{t}}{(1+i)^{\mathrm{t}}}$

Keterangan:

$\mathrm{Bt}=$ Penerimaan total pada tahun sekarang (Rp/tahun)

$\mathrm{Ct}=$ Biaya total pada tahun sekarang (Rp/tahun)

$\mathrm{T}=$ Tahun investasi (tahun)

I = Suku bunga discount factor(\%)

Dengan kriteria sebagai berikut:

a Apabila NPV bernilai positif (+), maka usaha menguntungkan dan layak untuk diusahakan. b Ababila NPV bernilai negatif (-), maka usaha tidak menguntungkan dan tidak layak untuk diusahakan.

\section{b.Net Benefit Cost Ratio (Net B/C)}

Menurut Gittinger (2008), Net B/C merupakan rasio antara manfaat bersih yang bernilai positif dengan manfaat bersih yang bernilai negatif. Kegiatan usahatani layak dilaksanakan apabila $\mathrm{Net} \mathrm{B} / \mathrm{C} \geq 1$ dan tidak layak dilaksanakan apabila Net $\mathrm{B} / \mathrm{C}<1$. Rumus perhitungan Net $\mathrm{B} / \mathrm{C}$ adalah sebagai berikut:

$$
N E T B / C=\frac{\sum_{t=0}^{n} \frac{B_{t}-C_{t}}{(1+i)^{t}}}{\sum_{t=0}^{n} \frac{B_{t-} C_{t}}{(1+i)^{t}}}
$$

Dimana :

$\mathrm{Bt}=$ Manfaat pada tahun ke-t

$\mathrm{Ct}$ = Biaya pada tahun ke- $\mathrm{t}$

$\mathrm{i}=$ Tingkat Diskonto (\%)

$\mathrm{n} \quad=$ umur proyek

$\mathrm{Bt}-\mathrm{Ct}=$ manfaat lebih besar dari biaya pada tahun ke-t

$\mathrm{Ct}-\mathrm{Bt}=$ biaya lebih besar dari manfaat pada tahun ke-t

\section{c. Internal Rate of Return (IRR)}

Menurut Gittinger (2008), IRR digunakan untuk melihat seberapa besar pembelian proyek terhadap investasi. IRR mengukur tingkat pengembalian proyek yang menghasilkan NPV sama dengan nol. Besaran yang dihasilkan dari perhitungan dalam satuan persentase. Kegiatan usaha 
tani jambu kristal dikatakan layak apabila $I R R \geq$ discount rate (i). Rumus yang digunakan adalah:

$$
I R R=i_{1}+\frac{N P V_{1}}{N P V_{1}-N P V_{2}}\left(i_{2}+i_{1}\right)
$$

Keterangan:

IRR = Internal Rate of Return (tingkat keuntungan internal).

$i 1=$ Tingkat diskonto untuk menghasilkan NPV1 positif mendekati nol. NPVI = Nilai NPV positif mendekati nol.

i2 = Tingkat diskonto untuk menghasilkan NPV2 negatif mendekati nol.

NPV2 = Nilai NPV negatif mendekati nol.

Dengan kriteria sebagai berikut:

a Jika $I R R>$ suku bunga yang berlaku, maka usahatani belimbing tersebut mampu mengembalikan imbalan jasa dari sejumlah modal yang diinvestasikan dan mendapat keuntungan.

b Jika $I R R$ < suku bunga yang berlaku, maka usahatani belimbing tersebut tidak mampu mengembalikan imbalan jasa dari sejumlah modal yang diinvestasikan dan mendapat kerugian.

c Jika $I R R=$ suku bunga yang berlaku, maka usahatani belimbing tersebut tidak mampu mengembalikan imbalan jasa dari sejumlah modal yang diinvestasikan namun tidak mendapat keuntungan.

\section{d. Payback Period (PP)}

Menurut Gittinger (2008), Payback Period (PP) digunakan untuk mengukur seberapa cepat investasi dapat kembali. Proyek dengan PP pendek atau pengembalian cepat, dinyatakan baik dan kemungkinan besar akan dipilih. Secara umum, rumus yang digunakan dalam perhitungan adalah:

$\mathrm{PP}=\mathrm{I} / \mathrm{Ab}$

Dimana:

I = biaya investasi kegiatan usahatani Belimbing

$\mathrm{Ab}=$ manfaat bersih yang didapat petani Belimbing setiap tahun

\section{Titik Impas Usahatani Belimbing}

Analisis titik impas atau Break Even Point (BEP) dilakukan untuk melihat produksi usahatani belimbing agar tidak mengalami kerugian. Menurut Soekartawi (1995), BEP dapat dihitung dengan rumus sebagai berikut

$B E P=\mathrm{TFC} / \mathrm{P}-\mathrm{AVC}$

Keterangan:

TFC $=$ Total biaya tetap usahatani belimbing $(\mathrm{Rp})$

$\mathrm{AVC}=$ Biaya variabel usahatani belimbing per $\mathrm{kg}(\mathrm{Rp} / \mathrm{kg})$

$\mathrm{P}=$ Harga jual belimbing per $\mathrm{kg}(\mathrm{Rp} / \mathrm{kg})$

Keberlanjutan usahatani belimbing ditinjau berdasarkan tiga aspek yaitu aspek ekonomi, aspek sosial dan aspek ekologi. 
Keberlanjutan usahatani belimbing diukur dengan menggunakan indeks keberlanjutan. Rumus indeks keberlanjutan adalah sebagai berikut.

Indeks keberlanjutan $=\frac{\text { skor yang diperoleh }}{\text { skor maksimum }} \times 100 \%$

Indeks keberlanjutan dibagi menjadi empat kategori status keberlanjutan sebagai berikut:

1. $0-25,00 \%$ : Tidak berkelanjutan.

2. 25,01-50,00\% : Kurang berkelanjutan.

3. $50,01-75,00 \%$ : Cukup berkelanjutan.

4. 75,01-100,00\% : Berkelanjutan.

\section{HASIL DAN PEMBAHASAN}

\section{Identitas Responden}

Tingkat pendidikan petani di Desa Wringinsari yang menjadi responden masih tergolong rendah. Petani Belimbing di Desa Waringinsari didominasi oleh lulusan Sekolah Dasar (SD) yaitu sebanyak
17 orang atau 68 persen dari jumlah responden.

Sebagian besar responden berada pada kelompok usia produktif (15-64), yaitu sebanyak 22 orang (94,00 persen) yang menunjukkan bahwa responden masih memiliki kemampuan fisik dalam melaksanakan usahataninya.

\section{Analisis Biaya Produksi Usahatani Belimbing}

Biaya usahatani belimbing memiliki komponen biaya usahatani yang terdiri atas biaya tetap dan biaya variabel. Hasil penjumlahan dari biaya tetap dan biaya variabel disebut biaya produksi atau biaya total dari usahatani belimbing.

Untuk lebih jelasnya rincian biaya produksi usahatani belimbing di Desa Waringinsari dalam tiga tahun dapat di lihat pada Tabel 1 
Tabel 1. Biaya Usahatani Belimbing Pertahun

\begin{tabular}{|c|c|c|c|c|}
\hline No & Uraian & $\begin{array}{c}\text { Tahun } 1 \\
\text { Nilai (Rp) }\end{array}$ & $\begin{array}{c}\text { Tahun } 2 \\
\text { Nilai (Rp) }\end{array}$ & $\begin{array}{l}\text { Tahun ke } 3 \\
\text { Nilai }(\mathbf{R p}) \\
\end{array}$ \\
\hline \multirow[t]{5}{*}{1} & Biaya tetap & & & \\
\hline & a. Pajak & 375.000 & 375.000 & 375.000 \\
\hline & b. Alat & 20.775 .000 & 20.775 .000 & 20.775 .000 \\
\hline & c. Penyusutan alat & --- & 5.417 .000 & 5.417 .000 \\
\hline & Total Fixed cost (TFC) & 21.150 .000 & 26.567 .000 & 26.567 .000 \\
\hline \multirow[t]{6}{*}{2} & Biaya tidak tetap & & & \\
\hline & a. Bibit & 15.975 .000 & 11.025 .000 & 12.150 .000 \\
\hline & b. Pupuk & 6.250 .000 & 4.687 .000 & 5.080 .000 \\
\hline & c.Tenaga Kerja & 21.606 .000 & 21.031 .000 & 21.189 .000 \\
\hline & Total variabel cost & 43.831 .000 & 36.743 .000 & 38.419 .000 \\
\hline & Total cost & 64.981 .000 & 63.310 .000 & 64.986 .000 \\
\hline
\end{tabular}

Tabel 1 menujukan biaya produksi usahatani belimbing pertahun, tahun pertama sebesar Rp 64.981.000 tahun ke dua sebesar Rp 63.310.000 dan tahun ke tiga sebesar Rp 64.986.000.

\section{Pendapatan Usahatani Belimbing}

Tabel 2. Pendapatan Petani Usahatani Belimbing Di Desa Waringinsari berdasarkan Cash in Flow, Cash Out dan Net Cash Flow

\begin{tabular}{cccc}
\hline $\begin{array}{c}\text { Umur } \\
\text { Tanaman }\end{array}$ & $\begin{array}{c}\text { Cash in } \\
\text { Flow }(\text { Rp })\end{array}$ & $\begin{array}{l}\text { Cash Out } \\
\text { flow }(\text { Rp })\end{array}$ & $\begin{array}{l}\text { Net Cash } \\
\text { Flow }(\text { Rp })\end{array}$ \\
\hline 1 & 34.080 .000 & 64.981 .000 & -30.901 .000 \\
\hline 2 & 74.520 .000 & 63.310 .000 & 11.210 .000 \\
\hline 3 & 125.916 .000 & 64.986 .000 & 60.930 .000 \\
\hline Total & $\mathbf{2 3 4 . 5 1 6 . 0 0 0}$ & $\mathbf{1 9 3 . 2 7 7 . 0 0 0}$ & $\mathbf{4 1 . 2 3 9 . 0 0 0}$ \\
\hline
\end{tabular}

Pendapatan pada tahun pertama masih mengalami kerugian, pada tahun pertama masih banyak pengeluaran untuk investasi usahatani belimbing, pada tahun ke 2 dan 3 mengalami kenaikan sehingga para petani bisa mendapatkan keuntungan.
Kelayakan finansial pada usahatani belimbing di Desa Waringisari

Analisis kelayakan pada usahatani Belimbing di Desa Waringinsari perlu dilakukan agar petani dapat mengetahui seberapa besar kelayakan dari usahatani tersebut sehingga apabila usahatani tersebut layak untuk diusahakan maka dapat dijadikan bahan pertimbangan bagi petani untuk meneruskan usahataninya atau tidak. Apabila usahatani Belimbing tersebut layak maka petani akan cenderung untuk tetap melakukan usatani Belimbing untuk selanjutnya, dan begitu juga sebaliknya. Berikut adalah hasil analisis kelayakan finansial pada usahatani Belimbing di Desa Waringinsari: 
Tabel 3. Hasil Perhitungan Kelayakan Finansial Usahatani Belimbing

\begin{tabular}{lll}
\hline Kriteria & Nilai & Keterangan \\
\hline NPV (DF 10\%) & 26.928 .881 & Layak \\
\hline Net B/C & 4,97 & Layak \\
\hline IRR & $59 \%$. & Layak \\
\hline PP & 4,7 & Layak \\
\hline
\end{tabular}

Berdasarkan perhitungan kelayakan finansial pada kriteria Net Present Value (NPV) diperoleh nilai NPV sebesar Rp 26.928.881,. Nilai NPV tersebut lebih besar dari nol (NPV > 0) sehingga dapat dikatakan layak diusahakan. Apabila dilihat dari besarnya nilai discount rate yang berlaku pada saat penelitian dilakukan dengan nilai discount rate $10,00 \%$ usahatani belimbing di Desa Waringinsari Kecamatan Langensari Kota Banjar layak untuk diusahakan, sedangkan apabila nilai discount rate mengalami kenaikan hingga 60,00\% maka usahatani belimbing tersebut tidak layak untuk diusahakan karena besarnya nilai NPV yang diterima pada tingkat discount rate tersebut bernilai negatif yaitu sebesar $\mathrm{Rp}$. -74.305 .

Nilai Net B/C yang diperoleh adalah sebesar 4.97 yang berarti bahwa output yang dihasilkan lebih besar 4.97 kali lipat dibandingkan dengan biaya yang dikeluarkan dalam usahatani belimbing. Nilai net B/C yang diperoleh sebesar 4,97 adalah lebih besar dari $1(\mathrm{Net} B / \mathrm{C}>1)$.

Hal tersebut menunjukkan bahwa usahatani pepaya di Desa Waringinsari secara finansial layak untuk diusahakan..

Berdasarkan tabel diperoleh hasil analisis finansial dengan kriteria IRR sebesar 59,00\%. Besarnya nilai IRR sebesar $59,00 \%$ menunjukkan bahwa usahatani belimbing di Desa Waringinsari Kecamatan Langensari Kota Banjar layak untuk diusahakan karena nilai IRR tersebut lebih tinggi dari tingkat suku bunga bank yang berlaku yaitu sebesar 10,00\% (Kredit BRI unit Langensari). Besarnya nilai IRR pada usatani belimbing menunjukkan bahwa penerimaan yang diterima petani mampu menutup biaya yang dikeluarkan, sehingga secara finansial usahatani belimbing sangat layak untuk diusahakan.

Nilai Payback Period (PP) sebesar 4,7 Hal ini dapat diartikan bahwa usahatani belimbing membutuhkan jangka waktu pengembalian investasi selama 4 tahun 7 bulan setelah mulai memperoleh penerimaan atau selama 4 tahun 7 bulan karena usahatani belimbing baru menghasilkan penerimaan pada tahun ke empat. 
Titik Impas (Break Even Point)

Tabel 4. Biaya, Produksi, Harga Jual, dan BEP Usahatani Belimbing di Desa Waringinsari

\begin{tabular}{ccc}
\hline No & Uraian & Jumlah \\
\hline 1 & Total biaya tetap (Rp) & 74.284 .000 \\
\hline 2 & Total biaya variabel (Rp) & 118.993 .000 \\
\hline 3 & Produksi pertahun (Kg) & 19.543 \\
\hline 4 & Biaya Variabel Rata-rata & $6.088,77$ \\
& (Rp/Kg/Tahun) (2/3) & \\
\hline 5 & Harga jual buah belimbing & 12.000 \\
\hline 6 & BEP Unit (Kg/Tahun) (1/(5- & 101,56 \\
& $4)$ & \\
\hline
\end{tabular}

Berdasarkan analisis Break Even Point (BEP) seperti pada tabel diatas, BEP unit atau kilogram belimbing per tahun yang minimal harus dihasilkan oleh petani belimbing adalah 101,56 kilogram. Hal tersebut menunjukkan bahwa pada usahatani belimbing di Desa Waringinsari harus terjual rata-rata 101,56 kilogram dalam satu tahun untuk mencapai titik impas atau keadaan seimbang dimana tidak terjadi kerugian atau mendapat keuntungan.

\section{Keberlanjutan Usahatani belimbing di} Desa Waringinsari

Keberlanjutan Usahatani belimbing dilihat dari berbagai dimensi seperti dimensi ekologi, ekonomi, dan sosial. Berikut adalah keberlanjutan pada masingmasing dimensi :

\section{Dimensi Ekonomi}

Tabel 5.Rata-Rata Skor Penilaian Keberlanjutan Usahatani Secara Ekonomi di Desa Waringinsari KecLangensari

\begin{tabular}{lll}
\hline No & Indikator & Skor \\
\hline 1 & Besarnya pemasaran buah belimbing & 1 \\
\hline 2 & Kemudahan dalam pemasaran Belimbing & 2,48 \\
\hline 3 & Kontribusi terhadap pendapatan petani Belimbing & 2,76 \\
\hline 4 & Kestabilan harga buah belimbing & 2,84 \\
\hline 5 & Sumber modal usahatani belimbing & 2,56 \\
\hline 6 & Tingkat produksi usahatani Belimbing & 3 \\
\hline 7 & Tingkat kemiskinan petani Belimbing & 2,52 \\
\hline 8 & Luas lahan garapan usahatani belimbing & 1 \\
\hline 9 & Aktif memperluas garapan usahatani belimbing & 2,64 \\
\hline 10 & Menggunakan bibit yang unggul & 3 \\
\hline 11 & Lembaga keuangan (Bank/ Kredit) & 2,28 \\
\hline Total & 26,08 \\
\hline Indeks Keberlanjutan $(\%)$ & 79 \\
\hline
\end{tabular}

Semakin besar pangsa pasar pemasaran atau rantai hilir hasil produksi usahatani belimbing, maka proses belimbing akan semakin baik sehingga 
memberikan peluang untuk keberlanjutan usahatani belimbing di Desa Waringinsari Kec Langensari. Berdasarkan hasil perhitungan yang dilakukan, indikator keberadaan usahatani belimbing memiliki nilai (1). Hal ini disebabkan karena pangsa pasar usahatani belimbing kecil, artinya bahwa hasil produksi belimbing hanya cukup untuk memenuhi pasar yang ada di Banjar sehingga belum bisa memenuhi pasar yang di luar Banjar. Hasil analisis indikator dimensi ekonomi hasilnya adalah berkelanjutan dengan skor (79\%).

\section{Dimensi Sosial}

Tabel 6. Rata-Rata Skor Penilaian Keberlanjutan Usahatani Secara Sosial di Desa Waringinsari Kec Langensari

\begin{tabular}{lll}
\hline No & Indikator & Skor \\
\hline 1 & $\begin{array}{l}\text { Program-program yang dibuat } \\
\text { pemerintah }\end{array}$ & 2 \\
\hline 2 & $\begin{array}{l}\text { Partisipasi kelompok tani } \\
\text { Belimbing }\end{array}$ & 2,44 \\
\hline 3 & $\begin{array}{l}\text { Tingkat pendidikan petani } \\
\text { Belimbing }\end{array}$ & 1,36 \\
\hline 4 & Motivasi petani bertani Belimbing \\
\hline 5 & $\begin{array}{l}\text { Pelatihan terkait keberlanjutan } \\
\text { Belimbing }\end{array}$ & 1,56 \\
\hline 6 & Status kepemilikan lahan & 2,8 \\
\hline 7 & Umur Petani Belimbing & 1,16 \\
\hline 8 & Penggunaan teknologi terbaru & 2 \\
\hline Total & & 15,92 \\
\hline Indeks keberlanjutan $(\%)$ & 66 \\
\hline
\end{tabular}

Petani belimbing tergabung ke dalam kelompok tani yang menjadi binaan BP3k Kecamatan Langensari sehingga program pemerintahan tiap tahun selalu ada untuk skor program pemerintahan untuk petani belimbing menunjukan (2) yang artinya pemerintahan tiap tahunnya selalu meluncurkan program untuk petani keberlanjutan belimbing. pelatihan untuk petani belimbing terkait keberlanjutan masih banyak yang tidak mau ikut pelatihan sebab masih kurangnya tingkat pendidikan di petani belimbing sehingga penggunaan teknologi baru masih terbilang jarang dari ketiga indikator skor yang di peroleh $(2,44),(1,36)$ dan (2) yang artinya masih dikatakan rendah dan masih perlu ada pembinaan lagi dari penyuluh pertanian. Status kepemilikan lahan belimbing sebagian besar milik sendiri dan sebagian sewa skor untuk kepemilikan lahan $(2,8)$ artinya kepemilikan lahan sedang, Keberlanjutan dimensi sosial dinyatakan cukup berkelanjutan yang menunjukan angka $66 \%$. 
Dimensi Ekologi

\begin{tabular}{llr} 
Tabel 7. Rata-Rata Skor Penilaian & Reratani \\
& Keberlanjutan & Usahatan \\
& Secara Ekologi & Desa \\
& Waringinsari Kec Langensari \\
\hline
\end{tabular}

\begin{tabular}{lll}
\hline NO & Indikator & Skor \\
\hline 1 & $\begin{array}{l}\text { Tingkat penggunaan pupuk oleh } \\
\text { petani }\end{array}$ & 1,56 \\
\hline 2 & $\begin{array}{l}\text { Pengendalian hama, penyakit } \\
\text { dan gulma di kebun }\end{array}$ & 1,6 \\
\hline 3 & Kebun pernah mengalami banjir & 2 \\
\hline 4 & Sumber air di dekat kebun dijaga & 2 \\
\hline 5 & Kesuburan lahan & 2,64 \\
\hline 6 & Tingkat pemanfaatan lahan & 1,68 \\
\hline Total & 11,48 \\
\hline Indeks keberlanjutan(\%) & 64 \\
\hline & Kesetabilan kualitas & $(1,52)$
\end{tabular}

Kesetabilan kualitas lahan $(1,52)$

artinya petani sangat tergantung terhadap tingkat penggunaan pupuk oleh petani belimbing masih banyak petani belimbing yang menggunakan pupuk anorganik yang menyebabkan lemahnya kualitas lahan, kesuburan lahan $(2,64)$ artinya lahan masih cukup bagus karena lahan pertanian yang berada di bantaran sungai memungkinkan setiap 3 bulan sekali terjadi banjir sehingga 3 bulan sekali lahan pertanian belimbing selalu diperbahurui unsur haranya, tingkat pemamfaatan lahan terbilang rendah $(1,68)$ dikarenakan masih banyak petani yang belum memanfaatkan lahan untuk usahatani belimbing, sumber air dikatakan cukup dijaga karena petani belimbing membuat saluran untuk menyirami lahan belimbing upaya yang dilakuakan untuk menjaga sumber air tetap terjaga petani selalu menanam pohon yang berpungsi untuk menyerap air hujan, keseluruhan dimensi ekologi dari beberapa indikator dapat artinya cukup keberlanjutan karena hasil skor didapat (64\%).

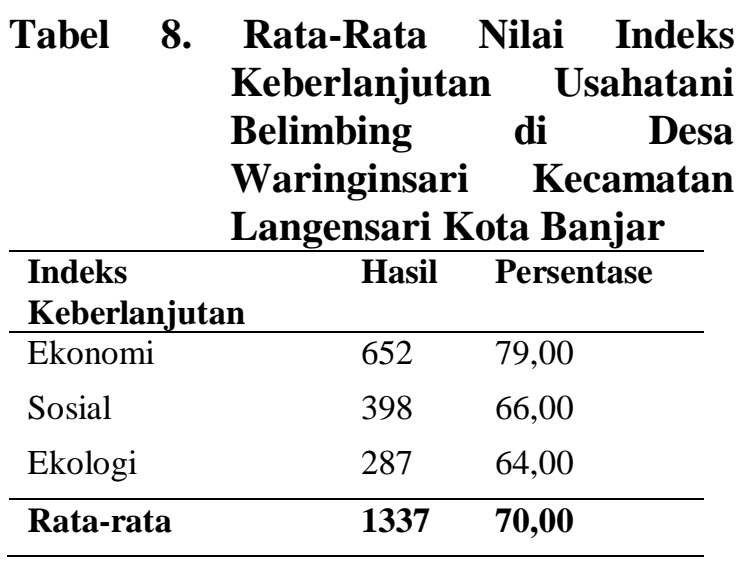

\section{KESIMPULAN}

Kelayakan usahatani belimbing di Desa Waringsari layak untuk dilaksanakan karena memenuhi kriteria investasi kelayakan berdasarkan Net Present Value, Net B/C, IRR dan Payback Period.

Titik impas Break Even Point (BEP) volume produksi adalah 101,56 kilogram dengan penjualan Rp12.000;perkilo, yang artinya usahatani belimbing tidak mengalami untung dan tidak merugi .

Keberlanjutan uasahatani belimbing secara keseluruhan dilihat dari aspek ekonomi, sosial dan ekologi tergolong cukup berkelanjutan (70 persen).

\section{SARAN}

Guna menjaga keberlanjutan usaha pertanian belimbing, pemerintah sebaiknya lebih sering membuat program-program terkait pertanian belimbing untuk para 
petani, diperlukan promosi terhadap buah belimbing baik di area Kota Banjar maupun di luar Kota Banjar serta mekanisme kerjasama antara sesama pelaku usahatani belimbing maupun antara pelaku petani dengan tujuan meningkatkan permintaan buah belimbing yang akan berdampak pada kestabilan harga, serta perlu dibentuk kelompok tani belimbing di berbagai Dusun di Desa Waringinsari agar dapat berperan dalam membantu petani anggota untuk meningkatkan produksi dan harga jual buah belimbing.

\section{DAFTAR PUSTAKA}

Anggreni Madik Linda, IGAA Ambarawati, I Nyoman Gede Ustriyana. 2018. Status Keberlanjutan Usahatani Padi Sawah Di Kota Denpasar (Studi Kasus Subak Intaran Barat, Desa Sanur Kauh, Kecamatan Denpasar Selatan). [jurnal] Manajemen Agribisnis,6 (1) $55-62$.
Ashari,sumeru.2006 meningkatkan keunggulan bebuahan tropis indonesia. Yogyakarta: ANDI
Badan Pusat Statistik Kota Banjar.2018.Kota Banjar Dalam Angka Banjar Municipality in Figures 2018.Kota banjar. BPS- Statistic of Banjar Municipality
Dinas Pertanian Dan Ketahanan Pangan rentra 2014-2018. 2014. Melalui https://banjarkota.go.id/wp- content/uploads/2019/08/banjarkota. go.id-informasi-publik-sakip-dinas- ketahanan-pangan-pertanian-dan-

perikanan-kota-banjar-1.-renstratahun-2014-2018-pdf.pdf.Html[05/04 120]

Direktorat Jenderal Hortikultura, Kementerian Pertanian. 2013. Statistik produksi hortikultura tahun 2013

Elida Novita, I.B.Suryaningrat, Idah Andriyani, dan Sukrisno Widyotomo. 2012. Analisis Keberlanjutan Kawasan Usaha Perkebunan Kopi (Kupk) Rakyat Di Desa Sidomulyo Kabupaten Jember. [jurnal] AGRITECH, 32 (2): 126135.

GEN, Global Ecovillage Network. 2005. CommunitySustainabiliy

Assessment. http://gen.ecovillage.org/activities/cs a/pdf/CSA-English.pdf [diunduh pada 2020 Mar 9].

Gintari GS.2017 Analisis Pendapatan Dan Keberlanjutan Usaha Pertanian Carica (Carica Pubescens) Di Kecamatan Kejajar, Kabupaten Wonosobo [Sripsi]. Bogor (ID): Institut Pertanian Bogor.

Gittinger JP. 2008. Analisa Ekonomi Proyek-Proyek Pertanian. Jakarta (ID): UIPress. (2): 57-69.

Gramedia

Hanafie, rita. 2010 pengantar ekonomi pertanian. Yogyakarta: ANDI

I Nyoman Gede Ustriyana, Ni Wayan Putu Artini. 2018. Analisis IndeksKeberlanjutan Usahatani Cabai Di Kabupaten Bangli. [jurnal] on Socio-Economics of Agriculture and Agribusiness, 12(1): 99-108 
Idin Saepudin Ruhimat.2015. Status Keberlanjutan Usahatani Agroforestry Pada Lahan Masyarakat: Studi Kasus Di Kecamatan Rancah, Kabupaten Ciamis, Provinsi Jawa Barat.[jurnal] Penelitian Sosial dan Ekonomi Kehutanan ,12 (2): 99-110

Jhon Wardie, Slamet Hartono, Dwidjono Hadi Darwanto, Irham. 2011. Analisis Usahatani Berkelanjutan Pada Rumahtangga Tani Di Daerah Lahan Pasang Surut Kalimantan Tengah.[jurnal] AGRISEP , 10(2): 259-272

Kanisius.

\section{Kementerian Pertanian I Basisdata Statistik Pertanian 1 BPS 1 tahun 2019. \\ Melalui.http://database.pertanian.go.i d/eksim2012/hasilEksporHs_dev.php . Html [ 05/04/20]}

Musfiqoh (2012). Panduan lengkap penulisan pendidikan. Jakarta: Prestasi Pustaka Publisher.

Nurm alina R, Tintin S, Arif K. 2010. Studi Kelayakan Bisnis. Bogor (ID): Departemen Agribisnis, Fakultas Ekonomi dan Manajemen, Institut Pertanian Bogor

Pasaribu, H. Ali musa.2012 kewirausahaan berbasis agribisnis.Yogyakarta : ANDI

Press).

Qori' Dian Pertiwi, Rudi Hartadi, Mustapit. 2014. Analisis Finansial dan Keberlanjutan Agribisnis Pepaya (Carica Papaya L.) di Desa Ledokombo Kecamatan Ledokombo Kabupaten Jember.[jurnal] Berkala
Ilmiah AGRIDEVINA,,3 (2): 125142

Rangkuti F. 2012. Studi Kelayakan Bisnis dan Investasi. Jakarta (ID): Kompas

Saida, S.Sabiham Widiatmaka, S. H. Sutjahjo. 2011. Analisis Keberlanjutan Usahatani Hortikultura Sayuran Pada Lahan Berlereng Di Hulu Das Jeneberang, Sulawesi Selatan. [jurnal] Matematika, Sains, dan Teknologi, 12(2): 101-112

Salikin KA. 2003. Sistem Pertanian Berkelanjutan. Yogyakarta (ID): Penerbit

Shinta A. 2011. Ilmu Usahatani. Malang (ID): Universitas Brawijaya Press (UB

Subdirektorat Statistik Hortikultura. 2019 .Statistik Tanaman Buah-buahan dan Sayuran Tahunan Statistics of Annual Fruit and Vegetable Plants Indonesia 2018. Jakarta.BPSStatistics Indonesia

Sugiyono. 2017. Metode penelitian pendidikan ( kuantitatif, kualitatif, dan R\&D).Bandung : Alfabeta

Sunarjono Hendro.2004 berkebun belimbing manis. Jakarta: penebar Swadaya

Suratiyah. 2006. Ilmu Usahatani. Penebar Swadaya. Jakarta.

Tati Budiarti, Suwarto, Istiqlaliyah Muflikhati. 2013. Pengembangan Agrowisata Berbasis Masyarakat pada Usahatani Terpadu guna Meningkatkan Kesejahteraan Petani dan Keberlanjutan Sistem Pertanian. [jurnal] lmu Pertanian Indonesia (JIPI), 18 (3): 200-207 


\section{Jurnal Ilmiah Mahasiswa AGROINFO GALUH}

Volume 8, Nomor 1, Januari 2021 : 59-72

Trijono, Rachmat. (2015). Metologi penelitian Kuanttitatif, Jakarta: Papas Sinar Sinanti.
Yudi triantoro.2010 Belimbing sepanjang tahun. Surabaya: SIC 